\title{
Determinants of the Performance of Insurance Companies in Tunisia
}

\author{
Abdelkader Derbali ${ }^{1,2}$ \& Lamia Jamel ${ }^{3,4}$ \\ ${ }^{1}$ Community College, Taibah University, Medinah, Saudi Arabia \\ ${ }^{2}$ Higher Institute of Informatics and Management, Kairouan University, Kairouan, Tunisia \\ ${ }^{3}$ College of Business Administration, Taibah University, Medinah, Saudi Arabia \\ ${ }^{4}$ Faculty of Economic Sciences and Management, Sousse University, Sousse, Tunisia \\ Correspondence: Abdelkader Derbali, Community College, Taibah University, Medinah, Saudi Arabia. Al Arith, \\ Medinah, Saudi Arabia. Tel: 966-543-495-251. E-mail: derbaliabdelkader@outlook.fr
}

Received: September 2, 2019 Accepted: October 3, 2019 Online Published: October 21, 2019

\begin{abstract}
This article aims to study the determinants of performance of Tunisian insurance companies for the period from 2002 to 2018 using the panel data method. The variables used are microeconomic and macroeconomic. Our results conclude that the determinants of the performance of Tunisian insurance companies are the capital structure, solvency, risk capital management, premium growth, volume of capital, age of the firm and financial investments.
\end{abstract}

Keywords: financial performance, performance determinants, Tunisian insurance companies

\section{Introduction}

In recent decades, a large literature has attempted to measure efficiency in the financial services sector. Many of the studies in this field have been concerned with the banking sector, for example Berger et al (1987), Ferrier and Lovell (1990) and Berger and Humphrey (1991). Studies in the life insurance sector are much less developed and the pioneers in this area are Cho (1986), Boose (1990) and Grace and Timme (1992).

In Tunisia, there are few studies on insurance. Chaffai and Ouertani (2002) and Zammit et al (2010) were the first to focus on the insurance sector. And in a context where the global economy is in turbulent times, measuring and studying the determinants of performance in the financial services sector is becoming a major issue.

Indeed, this sector deserves special attention because the subprime crisis originated in the banking sector and spread to the entire financial system. Starting from this framework of analysis, we have tried to study the performance factors of Tunisian insurance companies. To do this, we first studied the explanatory factors of efficiency. These factors may be microeconomic or macroeconomic variables.

The rest of the article will be organized as follows: In the second section, we will review the main studies on the determinants of the performance of insurance companies. In the third section, we describe the sample and the model used. In the fourth section, we present the results and their interpretations.

\section{Literature Review}

The literature examining the performance of insurance companies has attracted the attention of several researchers; especially the interest in understanding the factors responsible for financial performance. The performance of insurance companies is generally influenced by internal factors specific to insurance and external factors relating to the macroeconomic environment. Internal determinants can also be called microeconomic determinants.

\subsection{Microeconomic Determinants}

The academic literature provides evidence that suggests a strong relationship between the performance of insurance companies and several microeconomic factors. The latter which the literature proposes as important determinants, are: the size of the firm, the capital structure, the solvency, the leverage, the age of the firm, and so on.

The relationship between the size of the firm and the performance of insurance companies has been much discussed between researchers. Some show that size has a positive effect on performance such as Cummins and Rubio-Misas (2006), Eling and Luhnen (2010), Malik (2011) and Biener et al (2016) who consider that when the firm expands its performance increases; this is explained by achieving economies of scale. 
In the insurance industry, having to buy a lot of insurance premiums reduces income volatility because risk sharing is effective. Others suggest that very large companies suffer from economies of scale because it is difficult to manage a large insurance company, which leads to additional costs. Fenn et al (2008) and Mwangi and Murigi (2015) support this idea. In the same vein, the holding of capital by public authorities hampers performance.

Indeed, Neelaveni (2012) showed that private insurance companies perform better than public ones. In the same vein, Kumari (2013) indicates that there is a significant increase in the commercial performance of Indian life insurance companies after privatization. Solvency is the ability of a company to meet its long-term fixed expenses and thereby achieve growth.

Many studies have been conducted to determine the effect of solvency on the performance of insurance companies; Bawa and Chattha (2013) find a non-significant relationship between solvency and performance.

Several empirical studies have found a negative relationship between leverage and the performance of insurance companies like Malik (2011) who conducted a study on the Pakistani insurance sector and Wabita (2013) who conducted a study of insurance companies insurance in Kenya.

However Boadi et al (2013), conducting a study on insurance companies in Ghana found a positive but not significant relationship between leverage and insurance performance.

As for the age of the firm, it has been considered important in several studies; two streams of research exist. The first line of research argues that age could help companies become more efficient through learning.

Thus, older companies are more experienced and can benefit from learning, so they do not need innovations and can therefore take advantage of their superior performance as shown by Vigaykumar and Kadirvelu (2004) and Bates et al. (2008).

However, the second line of research shows that older societies are more bureaucratic and are not flexible enough to be able to adjust quickly to change, and can be overtaken by younger and more flexible firms.

\subsection{Macroeconomic Determinants}

In addition to the microeconomic variables, there are several empirical works that suggest that external factors like; GDP, interest rate, inflation, unemployment and M2 money supply; are important determinants of the performance of insurance companies.

Gross Domestic Product or GDP represents the market value of all finished goods and services produced in a country in a given year, and the increase in GDP generally reflects the household's disposition of larger income streams and the increased profitability of companies. The studies carried out on this subject confirm the existence of a positive relationship between GDP growth and the profit increase of the firm.

Oshinloye et al. (2009) point out that a country cannot achieve meaningful development without the existence of good insurance and that insurance is indispensable in any nation. Ezirim and Muoghahu (2002) add that insurance is seen as an indispensable tool for economic progress and growth and development.

Thus, insurance is closely linked with the country's economic growth. Crowley (2007) defines the interest rate as the price a borrower pays for the use of money borrowed from a lender. Economists support the idea that the interest rate is the price of the capital's speech over time; the monetarist uses the interest rate to attract more funds and as interest rate increases attract more savings and lower interest rates will encourage investors to look for other investments. Insurance companies themselves realize more income on their investments when interest rates rise but if these rates are too high this can affect the level of premiums.

Jhingan (2002) defines inflation as a persistent and substantial increase in the general level of prices and the price increase tends to deduce total household expenditures which in turn lead to lower GDP and reduce the wealth available to households. Thus, inflation can reduce insurance income by reducing the number of insurance policies written.

However, Molyneux and Thornthon (1992), Guru et al. (2002) and Abreu and Mendes (2002) have shown that there is a positive relationship between asset returns and inflation suggesting that the growth of inflation will be favorable to the increase in bank profits. The increase in the unemployment rate decreases the present and future purchasing power of households, which leads to a fall in the production of goods and services, because generally the fall in demand leads to a fall in supply. Unemployment has a negative impact on household cash flows and thus increases the burden of debt.

For companies, the increase in the unemployment rate may reduce production as a result of the fall in effective demand and, with regard to insurance companies, the increase in unemployment may reduce the number of 
insurance contracts and affect thus their income.

As regards the money supply, Haruna et al (2013) define it as the entire stock of money and other liquid payment instruments in the economy of a particular country at a specific time. The increase in the supply of money lowers interest rates, which in turn produce more investment.

\section{Presentation of the Sample and the Model Used}

\subsection{Sample}

The sample of our study is made up of thirteen resident insurance companies listed on the Tunisian Stock Exchange for the period from 2002 to 2018 . We only selected anonymous insurance companies for the sake of availability of data and for the homogeneity of the results, in addition the theoretical foundations are more applicable on these firms.

These insurances account for nearly $90 \%$ of the market share of the sector. The other six companies are excluded for lack of information on the period studied.

\subsection{Model}

In order to test the relationship between the independent variables and the financial performance of Tunisian insurance companies, we perform a linear regression analysis on panel data. The panel data has the property of combining two dimensions, the transversal dimension that is to say individual and the longitudinal dimension that is to say temporal. According to William et al (2010), the construction of a model implies the specification of relations between two or more variables; thus our model is generally defined by the following linear relation:

$$
\mathrm{yi}, \mathrm{t}=\alpha+\beta \mathrm{xi}, \mathrm{t}+\varepsilon \mathrm{i}, \mathrm{t}
$$

With:

- y: represents the dependent variable.

- $(\mathrm{i}, \mathrm{t})$ indicate the insurance and the year respectively.

$-\alpha$ : it is a constant.

- $\mathrm{x}$ : represents the vector of the independent variables.

- $\varepsilon i, t$ : represents the error.

We select 11 microeconomic variables and 8 macroeconomic variables for our study. By integrating the chosen variables, our model is as follows:

$$
\begin{gathered}
\mathrm{PF}=\alpha+\beta_{1} \mathrm{TAIL}+\beta_{2} \mathrm{STRC}+\beta_{3} \mathrm{LEV}+\beta_{4} \mathrm{SOL}+\beta_{5} \mathrm{CMR}+\beta_{6} \mathrm{VOC}+\beta_{7} \mathrm{CR}+\beta_{8} \mathrm{AGE}+\beta_{9} \mathrm{PLF}+\beta_{10} \mathrm{CR}+ \\
\beta_{11} \mathrm{TAILSEC}+\beta_{12} \mathrm{PIB}+\beta_{13} \mathrm{TI}+\beta_{14} \mathrm{INF}+\beta_{15} \mathrm{CH}+\beta_{16} \mathrm{M} 2+\beta_{17} \mathrm{POP}+\beta_{18} \mathrm{IC}+\beta_{19} \mathrm{VEH}+\varepsilon
\end{gathered}
$$

Table 1. Summary table of variables

\begin{tabular}{cccc}
\hline Variable & Notation & Measures & Expected sign \\
Financial performance & PF & $\begin{array}{c}\text { Dependent variable } \\
\text { ROA }=\text { Net result / Total assets } \\
\text { Independent variables } \\
\text { Microeconomic variables }\end{array}$ \\
Size of the insurance \\
company
\end{tabular}




\begin{tabular}{cccc}
\hline $\begin{array}{c}\text { Premium growth } \\
\text { Age }\end{array}$ & CRP & LN of the age of the firm & $(-)$ \\
Financial investments & PLF & Financial investments / Total assets & LN of Total Assets Variable \\
Premiums first three insurance / Total & $(+/)$ \\
Concentration index & CR & $(?)$ \\
Size of the insurance & TAILSEC & Total assets insurance sector / GDP & $(+)$ \\
sector & & Macroeconomic variables & $(+)$ \\
& PIB & Annual GDP growth & \\
GDP growth & TI & Director interest rate & $(+)$ \\
Interest rate & INF & Inflation rate & $(+)$ \\
inflation & CH & Unemployment rate & $(-)$ \\
Unemployment & M2 & M1 + quasi money & $(-)$ \\
M2 money supply & POP & Annual growth rate & $(+-)$ \\
Population & IC & Corruption perception index & $(+)$ \\
Corruption & VEH & Number of motor vehicles per 1000 & $(-)$ \\
Number of vehicles & & people. & $(+)$ \\
\hline
\end{tabular}

\section{Presentation and Analysis of the Results}

To determine the proper estimation method of the equation, we performed some tests.

The modified Wald test makes it possible to test the specific hypothesis of inter-individual homoscedasticity. The null hypothesis assumes that the variance of the errors is the same for all individuals.

The result of this test is equal to 0.0000 so we deduce the presence of heteroscedasticity between individuals. The Breush-Pagan test makes it possible to detect intra-individual heteroskedasticity which assumes different variances between the error terms of the same individual.

The result of this test leads us to accept the null hypothesis and indicates the presence of homoscedasticity. The Hausman test makes it possible to determine whether the coefficients of the two estimates (fixed and random) are statistically different. This test compares the variance-covariance matrix of the two estimators.

The result of this test is equal to 0.0000 so we reject the null hypothesis and we must favor the adoption of a fixedeffect model. The estimation of the parameters of our model by the Ordinary Lesser Square method gave the following results:

Table 2. Result of estimates

\begin{tabular}{ccc}
\hline Independent Variables & Values & t-student \\
\hline TAIL & -0.008 & -1.24 \\
STRC & $-0.011 * *$ & -2.09 \\
LEV & $(0.039)$ & -0.07 \\
SOL & -0.0002 & 2.32 \\
CMR & $(0.95)$ & -2.44 \\
VOC & $\left(0.077^{* *}\right.$ & 2.78 \\
CRP & $-0.136^{* * *}$ & -2.46 \\
AGE & $0.017 * * *$ & $-2.016)$ \\
PLF & $(0.006)$ & -1.64 \\
\end{tabular}




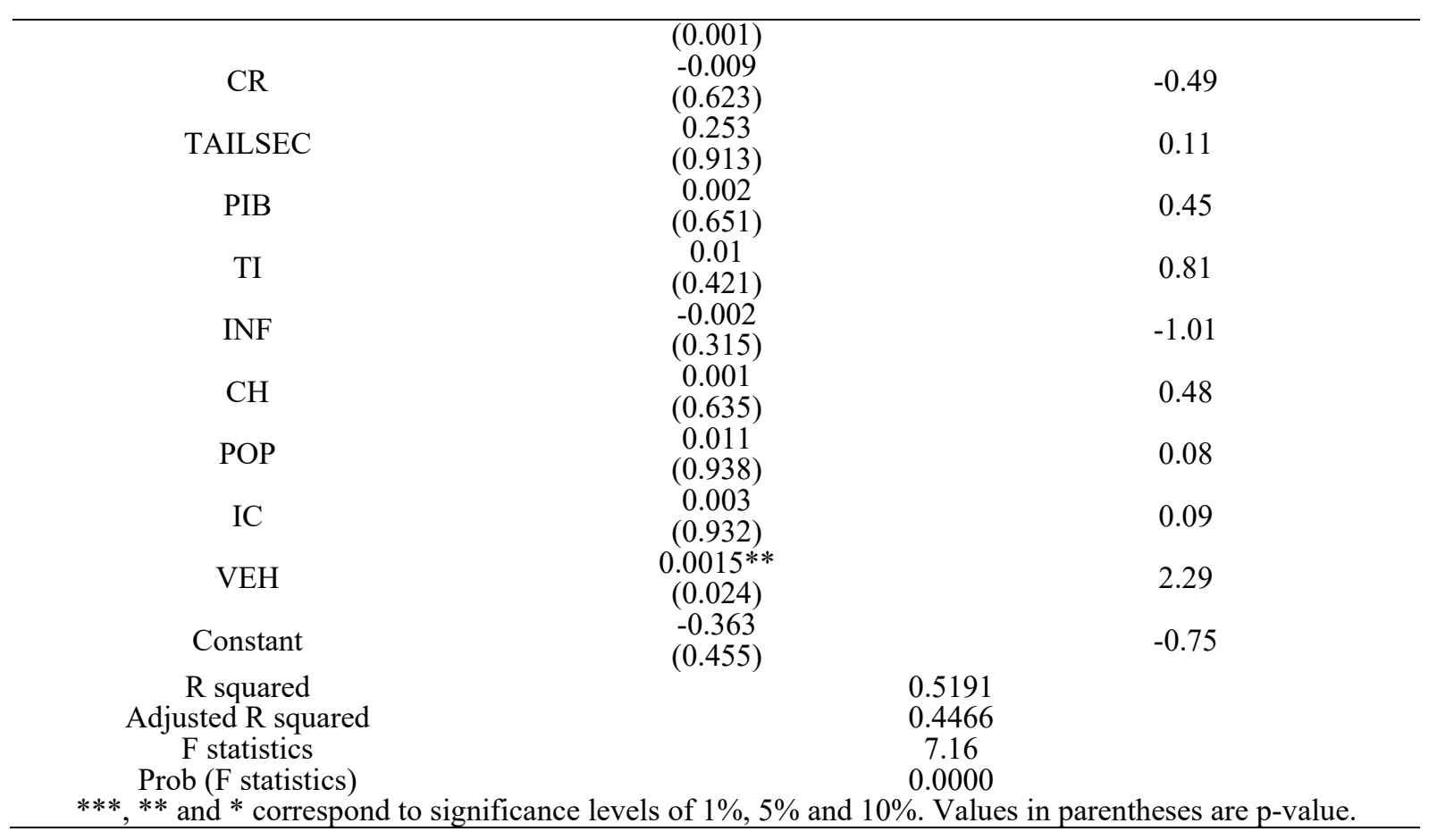

The value of Adjusted $\mathrm{R}$ square is $44.66 \%$ and the $\mathrm{R}$ square of the model is $51.91 \%$. This means that $51.91 \%$ of the variations in the dependent variable (PF) are explained by the regression model. The Fisher statistic has a pvalue equal to 0.0000 ; the model is therefore statistically significant.

The variable "TAIL" has a negative but statistically insignificant effect on the performance of Tunisian insurance companies. Indeed, an increase in Ln TAIL leads to a decrease in the financial performance of insurance. This means that the biggest insurers are less efficient and so smaller companies are more efficient. This result is consistent with those of Yuengert (1993), Mwangi and Iraya (2014) and Zanghieri (2008).

The significance of the capital structure variable "STRC" implies that the latter is a determining factor in the financial performance of Tunisian insurance companies. The negative sign of the coefficient attached to this variable is consistent with that anticipated. So capital ownership by the state negatively affects the performance of Tunisian insurance and private companies are subsequently performing better. This result is consistent with that of Neelaveni (2012).

The variable "LEV" or financial leverage has a negative but insignificant sign on the performance of Tunisian insurance companies. In fact, the increase in the level of debt relative to equity raises insurance costs and therefore leads to a decline in its financial performance. This result is consistent with those of Malik (2011) and Wabita (2013).

On the other hand, the variable "SOL" has a positive and statistically significant sign. So the solvency of the insurance has a positive effect on its financial performance. This result is consistent with that anticipated.

The variable "CMR" or risk capital management has a negative sign statistically very significant. So a large share of capital and reserves relative to total assets negatively affects the performance of insurance and insurance companies that hold a smaller share of capital and reserves are subsequently more successful. This result is consistent with that anticipated.

The "CRP" variable, which represents premium growth, also has a statistically significant negative sign. This implies that rapid and excessive growth in premium volume is hampering the performance of insurance companies as such growth creates more risk and a requirement to hold more technical reserves. This result confirms those of Charumathi (2012) and Kim et al (1995).

The capital volume variable "VOC" has a positive and statistically significant sign. Indeed, an increase in LnVOC leads to an increase in the financial performance of insurance. This implies that insurance that holds a larger volume of capital is more efficient than insurance that holds less. This result is consistent with that anticipated.

The variable "AGE" has a negative and statistically significant sign. So in the Tunisian insurance sector, the older 
the firm, the less efficient it is and the newly created insurance are more efficient. This result invalidates the work of Vigaykumar and Kadirvelu (2004).

The new variable "PLF" or financial investments has a positive and statistically significant sign. The significance of this variable implies that the latter is a determining factor in the performance of Tunisian insurance companies. The positive sign of the coefficient attached to financial investments shows that insurance companies that have a larger share of financial investments are performing better. This can be explained by the fact that income from financial investments, in addition to other income, increases the result of the insurance company and subsequently its performance.

The "CR" variable that represents the market concentration index has a negative and statistically insignificant sign. The negative sign of this variable shows that a high concentration of the market hinders the performance of insurance companies. This result is not consistent with our hypothesis.

The variable "TAILSEC" which represents the size of the insurance sector has a positive but statistically insignificant sign. The positive sign of this variable implies that the size of the sector positively affects the performance of insurance companies. The non-significance of this variable is the result of the difficulty experienced by Tunisian insurance companies in taking advantage of the economies of scale they can achieve through this sector.

The "GDP" variable, which represents annual GDP growth, has a positive but statistically insignificant sign. So GDP growth positively affects the performance of insurance companies. This is because the country's economic growth has positive effects on business sectors, including the insurance sector. The non-significance of this variable shows that Tunisian insurance companies do not benefit from the country's economic growth.

The variable "TI" or interest rate has a positive and statistically insignificant sign. Thus, the increase in the interest rate positively affects the performance of insurance companies. In fact, bonds represent a large part of the inverted assets of insurance companies and the increase in interest rates brings higher bond income. The non-significance of this variable shows that Tunisian insurance companies do not use these revenues effectively.

The "INF" variable for inflation has a negative and statistically insignificant sign. The increase in inflation has a negative effect on insurance companies. This is explained by the fact that the increase in the consumer price index affects insurance performance by increasing the number of claims, expenses and technical provisions.

The variable "CH" or unemployment has a positive and statistically insignificant sign. Thus the increase in the unemployment rate has a positive effect on the performance of insurance companies. This result is contrary to our expectations.

The money supply variable "M2" has a negative and statistically insignificant sign. So the increase in money supply negatively affects the performance of insurance companies. This is explained by the fact that the increase in the money supply increases inflation if it is not correlated with the economic growth of the country.

The variable "POP" which represents the annual growth rate of the population has a statistically insignificant positive sign. Indeed, the increase in the population leads to an increase in the performance of insurance companies. This can be explained by the increase in the number of potential customers. The non-significance of this variable shows that Tunisian insurance companies do not take advantage of this opportunity.

The variable "IC" which represents the perception index of corruption has a positive but statistically insignificant sign. The increase in corruption has a positive effect on the performance of insurance companies. This result is surprising and contrary to our expectations.

The variable "VEH" which represents the number of vehicles has a positive and statistically significant sign. Thus, the increase in the number of motor vehicles has a positive effect on the performance of insurance companies. This is explained by the fact that the automobile branch dominates the Tunisian insurance sector. This result is consistent with that anticipated.

\section{Conclusion}

At the level of this work, we have tried to determine the factors that can influence and affect the performance of Tunisian insurance companies during the period 2002-2018. The interpretation of the results has allowed us to understand that only the microeconomic factors are determinant of the performance of insurance companies. Macroeconomic factors do not have significant effects on performance. Capital structure, solvency, risk capital management, premium growth, volume of capital, age and financial investments are the determinants of the performance of Tunisian insurance companies.

Thus, the performance of an insurance company is a set of determinants that are related to the activities of that 
company. Each determinant must be carefully managed so that the results of the activities are positive and satisfactory and meet the expectations of all stakeholders.

As a research perspective, the analysis can be continued by applying to other MENA countries that are subject to the same regulatory implications as Tunisia to see if there is a country where the insurance sector is performing well. It may also be interesting to know if the insurance sectors of other countries are affected by the crisis.

\section{Declaration of interest}

The authors report no conflicts of interest. The authors alone are responsible for the content and writing of the paper.

\section{Acknowledgments}

I think to knowledge the Editor in Chief and the anonymous reviewers for their supportive remarks.

\section{References}

Berger A. N., \& Humphrey, D. B. (1991). The dominance of inefficiencies over scale and product mix economies in banking. Journal of Monetary Economics, 28. https://doi.org/10.1016/0304-3932(91)90027-L

Berger. A, H., \& Humphrey, D. (1987). Competitive viability in banking: Scale, scope and product mix economies. Journal of Monetary Economics, 20. https://doi.org/10.1016/0304-3932(87)90039-0

Biener, C., \& Wirfs, J. (2016). The determinants of efficiency and productivity in the Swiss insurance industry. European Journal of Operational Research, 248. https://doi.org/10.1016/j.ejor.2015.07.055

Charumathi, B. (2012). On the Determinants of Profitability of Indian Life Insurers - An Empirical Study. Proceedings of the World Congress on Engineering, London, U.K.

Cho, D. (1988). Measuring scale economies of the insurance industry: An analysis of multiple regression models. Journal of insurance issues and practices, 11.

Eling, M., \& Luhnen, M. (2010). Efficiency in the international insurance industry: Across-country comparison. Journal of Banking and Finance, 34(7). https://doi.org/10.1016/j.jbankfin.2009.08.026

Ferrier, G. D., \& Lovell, C. (1990). Measuring Cost Efficiency in Banking - Econometric and Linear Programming Evidence. Journal of Econometrics, 4, 229-245. https://doi.org/10.1016/0304-4076(90)90057Z

Kumari, T. H (2013). Performance Evaluation of Indian Life Insurance Industry in Post Liberalization. International Journal of Social Sciences Arts and Humanities, 1.

Malik, H. (2011). Determinants of insurance compagnies profitability: An anlysis of insurance sector of Pakistan. Academic Research International, 1(3).

Molyneux, P., \& Thornton, J. (1992). Determinants of european bank profitability: A note. Journal of banking and finance, 16. https://doi.org/10.1016/0378-4266(92)90065-8

Mwangi, M., \& Cyrus, I. (2014). Determinants of Financial Performance of General Insurance Underwriters in Kenya. International Journal of Business and Social Science, 5(13).

Mwangi, M., \& Murigu, J. (2015). The determinants of financial performance in general insurance compagnies in Kenya. European Scientific Journal, 11(1).

Neelaveni, V. (2012). Financial Performance of Life Insurance Companies and Products. Zenith International Journal.

Wabita, F. M. (2013). Determinants of Financial Performance of Insurance Companies in Kenya. University of Nairobi unpublished Master of Science in Finance project.

William, G., Zikmund, B. J., Babin, J. C., \& Carr, G. (2010). Research Business Methods (8th ed). Canada.

Yuengert, A. M. (1993). The measurement of life insurance: Estimates of a mixed normal-gamma error model. Journal of Banking and Finance, 17(2-3). https://doi.org/10.1016/0378-4266(93)90047-H

\section{Copyrights}

Copyright for this article is retained by the author(s), with first publication rights granted to the journal.

This is an open-access article distributed under the terms and conditions of the Creative Commons Attribution license (http://creativecommons.org/licenses/by/4.0/). 